\title{
Earthquake Prediction System using Neuro-Fuzzy and Extreme Learning Machine
}

\author{
Basuki Rahmat ${ }^{1}$ \\ Department of Informatics Engineering \\ Universitas Pembangunan Nasional "Veteran" Jawa Timur \\ Surabaya, Indonesia \\ 'basukirahmat.if@upnjatim.ac.id
}

\author{
Fitri Afiadi ${ }^{2}$ \\ Indonesia's Agency for Meteorological Climatological and \\ Geophysics Region II \\ Tangerang, Indonesia \\ 2fitriafiadi@gmail.com,
}

\author{
Endra Joelianto ${ }^{3}$ \\ Engineering Physics \\ Institut Teknologi Bandung \\ Bandung, Indonesia \\ ${ }^{3}$ ejoel@tf.itb.ac.id
}

\begin{abstract}
Knowledge of earthquake predictions is very important, especially to recognize patterns of occurrence. This paper proposes an earthquake prediction system, in the form of b-value predictions as parameters that indicate the potential for earthquakes. The methods used are neuro-fuzzy with ANFIS structure and Extreme Learning Machine (ELM). From the experimental results, it shows that the ELM method has better performance than Neuro-fuzzy with ANFIS structure.
\end{abstract}

Keywords-neuro-fuzzy; ANFIS; extreme learning machine; ELM; earthquake; prediction.

\section{INTRODUCTION}

An earthquake is a vibration that occurs on the surface of the earth due to the sudden release of energy that creates seismic waves. Earthquakes are usually caused by the movement of the Earth's crust (Earth's plate). The frequency of an area refers to the type and size of the earthquake experienced over a period of time. Earthquakes are measured using a Seismometer tool. Moment magnitudes are the most common scale where earthquakes occur for the whole world.

Indonesia is one of the countries prone to earthquakes because it is located in the area of meeting three major tectonic plates namely the Pacific Plate, the Indo-Australian Plate and the Eurasian Plate[1].The plates are relatively moving between one another, where the Indo-Australian Plate moves from south to north, and the Eurasian Plate moves from north to southsoutheast to meet along the west of South Sumatra, Java, Nusa Tenggara, and ends on the southern part of the Palu-Koro fault in the southeast of Sumba Island.Features of subduction zones and of oceanic crust and mantle of the Indonesian regionas shown in Fig. 1 [1].

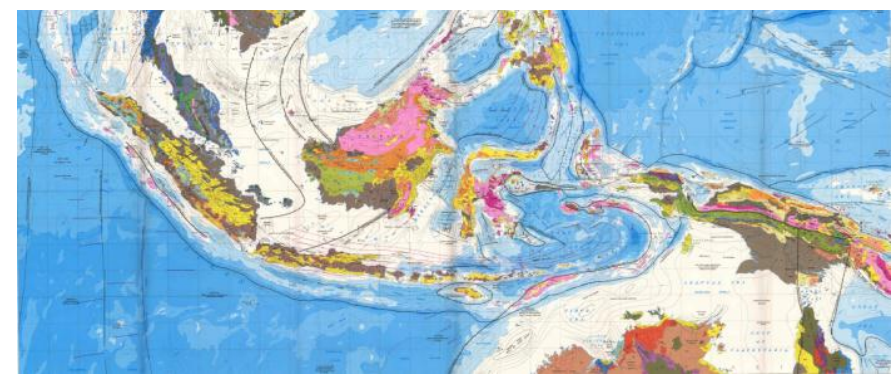

Fig. 1. Features of subduction zones and of oceanic crust and mantle of the Indonesian region.

The Sumatra region is part of the Sunda archipelago, which extends from the Andaman-Nicobar archipelago to the Banda arc (Timor). The Sunda arc is an archipelago arising from the interaction of the oceanic plate (the Indo-Australian plate moves north at a speed of $7 \mathrm{~cm}$ per year) which falls beneath the continental plate (Eurasian Plate). Plate subduction occurs south of the Sunda arc in the form of a trench. Also, the subduction of the plate forms a range of volcanoes and volcanic hills (rows of hills) along the Sumatran mainland and the Sumatra fault (Sumatra Fault) which divides the Sumatra mainland [2].

The Sumatra-Andaman region is one of the active quake regions in the world. It has a unique tectonic pattern, in the west of Sumatra stretches the subduction zone area parallel to the coastline of Sumatra, on the land extending the Sumatra fault which divides Sumatra Island into two, from the Andaman Bay at the north end to Semangko Bay at the south end parallel to the zone straightness subduction [3]. Recorded in the last decade there have been three major earthquakes, namely the December 26, 2004 Aceh earthquake, the March 28, 2005 earthquake, and the Padang earthquake of September 30,2009 . The earthquake that occurred in this region has claimed many lives and property. 
This research proposes an earthquake prediction method for the Sumatra region based on earthquake occurrence data from previous years. The research location is limited to Sumatra Region from $92^{\circ}-106^{\circ}$ East Longitude (EL) and $6.5^{\circ}$ South Latitude (SL) $-8^{\circ}$ North Latitude (NL). The prediction methods used in this research are the Neuro-Fuzzy with Adaptive Neuro-Fuzzy Inference System (ANFIS) structure and Extreme Learning Machine (ELM). These methods are used to identify earthquake time series prediction based on training data. The aim is to predict b-values that describe the seismotectonic state of a region that can be seen from the relative frequency of large earthquakes and small earthquakes that occur. The estimated earthquake parameters of this bvalue as a strong earthquake precursor based on time series data, without taking into account the characteristics of other earthquake physical parameters.

Some research on ANFIS for prediction can be mentioned as follows: [4-7]. Likewise, some ELM applications for prediction can be read in the following references: [8-12].

\section{Spatial VARIATIONS IN SEISMICITY}

The relationship of frequency-magnitude (FrequencyMagnitude Distribution, FMD) is one way to determine seismic activity in an area (Fig. 2). FMD from earthquakes was first put forward by Gutenber-Richter[13], which is a power law. Globally the b-value approaches 1 , which means that 10 times the decrease in activity is related to the increase in each unit of magnitude. This relationship is known as the GutenbergRichter relation, written as in (1):

$$
\log N(M)=a-b M
$$

Where $\mathrm{n}(\mathrm{M})$ is the number of earthquakes with magnitude M. Whereas the a-value is a seismic parameter whose magnitude depends on the number of earthquakes and for certain regions depending on the determination of volume and time window.

The constant $\mathrm{b}$ is a tectonic parameter, indicated by the slope of the FMD curve in Fig. 2. Empirically according to Wiemer \& Wyss [14], the size of b-value has a range from 0.4 to 2.0, and can describe the seismotectonic state of an area which is seen from the relative frequency of the earthquake, big and small earthquake that happened. If an area regularly produces small earthquakes and rarely produces large earthquakes, the frequency-magnitude curves will be sharper and the curve gradient (b-value) will be greater than the area that rarely produces small earthquakes but occasionally releases large earthquakes. The fundamental parameters that affect large b-values are the accumulation of stress acting on rocks, low b-values associated with high-stress shear, and vice versa. Based on this concept Schorlemmer \& Wiemer [15] make b-value a stress measure.

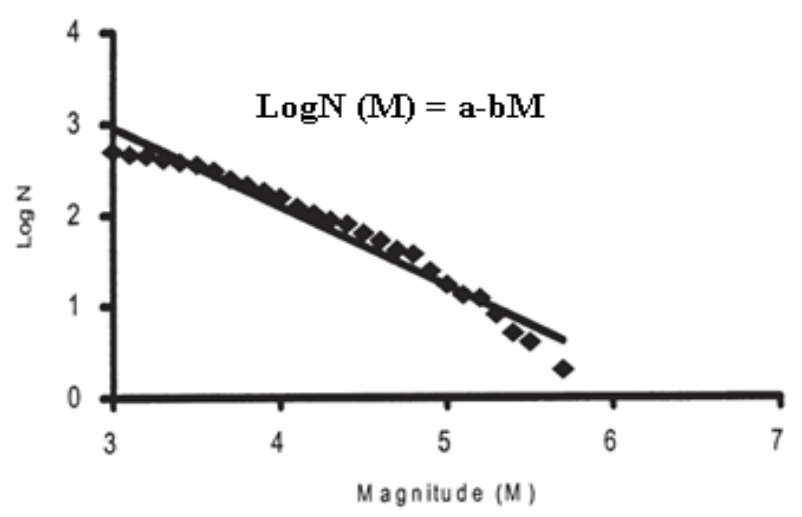

Fig. 2. Gutenberg-Richter relation that describes the relationship between the logarithm of a number of earthquakes and magnitude.

The b-value parameter can be determined by the least square method or the maximum likelihood. The maximum likelihood method uses the equation given by Utsu [16] as in (2).

$$
\delta b=2.30 b^{2} \sqrt{\sum_{i=1}^{n} \frac{\left(M_{i}-\bar{M}\right)^{2}}{n(n-1)}}
$$

Where $M$ is the average magnitude, and $M$ min is the minimum magnitude. The standard deviation uses formulas from Shi and Bold [17] as in equation (3).

$$
b=\frac{\log e}{M-M_{\min }}=\frac{0.4343}{M-M_{\min }}
$$

Where $\mathrm{n}$ is the number of earthquakes at the sampling calculation.

Research on spatial and temporal variations of b-values has been widely carried out, including research by Kumar[18] regarding the correlation of spatial and temporal variations of b-values to earthquake events and their relation to fractal dimensions in the Himalayan fault. Analysis of the correlation between spatial and temporal b-value variations on stress, seismicity, and tectonics in Bali, Lombok and Sumbawa by Pratiwi[19], while Sunardi [20] analyzed the relationship between fractal dimensions and the Bali-NTB slip ratio based on variation mapping tectonic parameters. Research in the Indonesia region was carried out by Rohadi [21] showing that variations in spatial a-value ranged from 4.0 to 12.1 and variations in $b$-value ranged from 0.6 to 1.8 , while the return period of the $\mathrm{M}$ earthquake ranged from 6.5 to $4-12$ years.

\section{Proposed Methodology}

\section{A. Research Data}

The data used in this research are earthquake data from the International Seismological Center (ISC) catalog of the Sumatra-Andaman region, covering the limits of $92^{\circ}-106^{\circ}$ East Longitude (EL) and $6.5^{\circ}$ South Latitude (SL) - $8^{\circ}$ North Latitude (NL), the period of January 1973 - November 2014. Magnitude is greater than 3.0 SR, with a depth of less than 300 $\mathrm{km}$. 
The b-value change curve on average for time for the entire research area is shown in Fig. 3. The red bars indicate when a large earthquake occurred with $M>6.5$. The curve shows almost all the occurrences of earthquakes $M>6.5$ which approached the ideal condition, namely the b-value experienced a decline in the period close to the time of the earthquake and experienced an increase in the interval of $<1$ year.

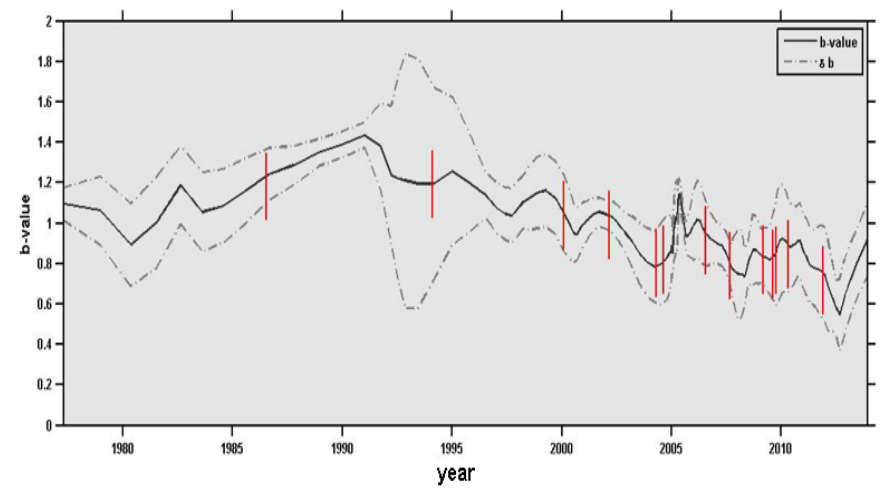

Fig. 3. The plot of b-value is averaged over time

\section{B. Model Structure}

The data used is b-value data from January 1973 November 2014, or as many as 455 months. For ease of data format, only 450 months are used. The model structure of the training data and validation data from this research is designed as shown in Fig. 4.

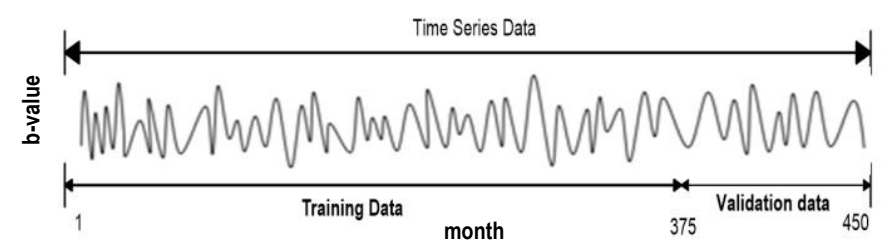

Fig. 4. The model structure of $b$-value training data and validation data

\section{ANFIS Structure}

By the training data and validation data format in Fig. 4, then the ANFIS structure for Forward Pass and Backward Pass is designed with 4 inputs and 1 output, as shown in Fig. 5 and Fig. 6.The processes in each layer with each node given $n 1$ to $\mathrm{n} 21$ notation, are described as follows.

\section{Forward Pass}

Layer 1:

In the layer 1 the fuzzification process is applied, using the fuzzy Bell membership function, as in equation (4).

$$
n i=\frac{1}{1+\left|\frac{x-c_{i}}{a_{i}}\right|^{2 b_{i}}}
$$

Where $\mathrm{i}=1, \ldots, 8 ; \mathrm{n} 1, \ldots, \mathrm{n} 8$ are membership functions; $\mathrm{x}$ is input; $\left\{a_{i}, b_{i}, c_{i}\right\}$ are each set of fuzzy membership function premise parameters.
Layer 2:

In this layer applied AND fuzzy logic as a function node, the output node is as in (5).

$$
\begin{aligned}
& \mathrm{n} 9=\min (\mathrm{n} 1, \mathrm{n} 3) \\
& \mathrm{n} 10=\min (\mathrm{n} 2, \mathrm{n} 4) \\
& \mathrm{n} 11=\min (\mathrm{n} 5, \mathrm{n} 7) \\
& \mathrm{n} 12=\min (\mathrm{n} 6, \mathrm{n} 8)
\end{aligned}
$$

Layer 3:

In this layer, it normalizes the incoming signal. Suppose ntot= $\mathrm{n} 9+\mathrm{n} 10+\mathrm{n} 11+\mathrm{n} 12$, then this layer output is obtained as (6).

$$
\begin{aligned}
& \mathrm{n} 13=\mathrm{n} 9 / \text { ntot } \\
& \mathrm{n} 14=\mathrm{n} 10 / \text { ntot } \\
& \mathrm{n} 15=\mathrm{n} 11 / \text { ntot } \\
& \mathrm{n} 16=\mathrm{n} 12 / \text { ntot }
\end{aligned}
$$

\section{Layer 4:}

In this layer, the Least Square Estimator method is applied to obtain consistent parameters $(\theta(1), \ldots, \theta(20))$. If input 1 is shortened to in1, input 2 as in2, input 3 as in 3 , input 4 as in 4 , thenthis layer output as in (7) and (8).

$$
\begin{aligned}
& f 1=\theta(1) \cdot \operatorname{in} 1+\theta(2) \cdot \operatorname{in} 2+\theta(3) \cdot \operatorname{in} 3+\theta(4) \cdot \operatorname{in} 4+\theta(5) \\
& f 2=\theta(6) \cdot \operatorname{in} 1+\theta(7) \cdot \operatorname{in} 2+\theta(8) \cdot \operatorname{in} 3+\theta(9) \cdot \operatorname{in} 4+\theta(10)(7) \\
& f 3=\theta(11) \cdot \operatorname{in} 1+\theta(12) \cdot i n 2+\theta(13) \cdot i n 3+\theta(14) \cdot i n 4+\theta(15) \\
& f 4=\theta(16) \cdot \operatorname{in} 1+\theta(17) \cdot \operatorname{in} 2+\theta(18) \cdot \operatorname{in} 3+\theta(19) \cdot \operatorname{in} 4+\theta(20) \\
& \text { n17 }=\text { n13.f } \\
& \text { n18 }=\text { n14.f } \\
& \text { n19 }=\text { n15.f3 }
\end{aligned}
$$$$
\mathrm{n} 20=\mathrm{n} 16 . \mathrm{f} 4
$$

\section{Layer 5:}

In this layer 5, the output means the ANFIS network output, which is the sum of all incoming signals, as in (9).

$$
\mathrm{n} 21=\mathrm{n} 17+\mathrm{n} 18+\mathrm{n} 19+\mathrm{n} 20
$$

\section{Backward Pass}

Furthermore, to correct the ANFIS network output error, the gradient descent method with Error Backpropagation (EBP) is used, in the Backward Pass process. Error correction from the results of the EBP process from layer 5 to layer 1, denoted in $\varepsilon_{21}, . ., \varepsilon_{1}$, as shown in Fig. 6 . 


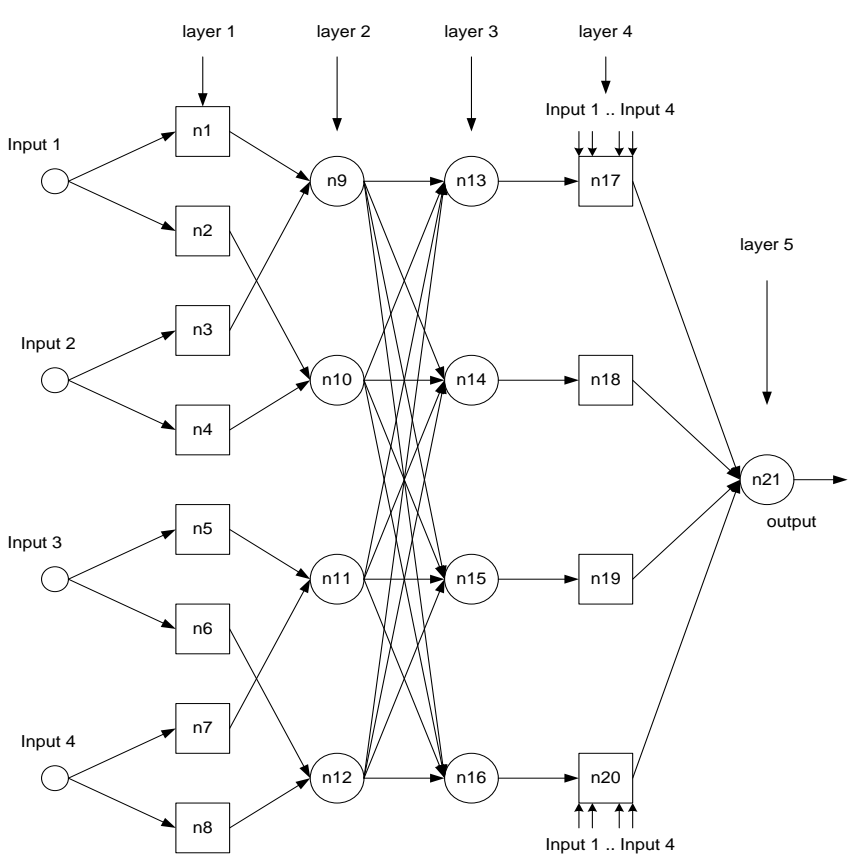

Fig. 5. The Forward Pass ANFIS structure

\section{ELM structure}

ELM is a new learning method of Artificial Neural Networks (ANN). This method was first introduced by Huang[22]. ELM is a feedforward ANN with a single hidden layer or commonly called Single Hidden Layer Feedforward Neural Networks (SLFNs).

ELM learning method is made to overcome the weaknesses of feedforward ANN especially regarding learning speed. Two reasons why feedforward ANN has a low learning speed are[22]:

1. Using a slow gradient-based learning algorithm for training.

2. All parameters in the network are determined iteratively by using the learning method.

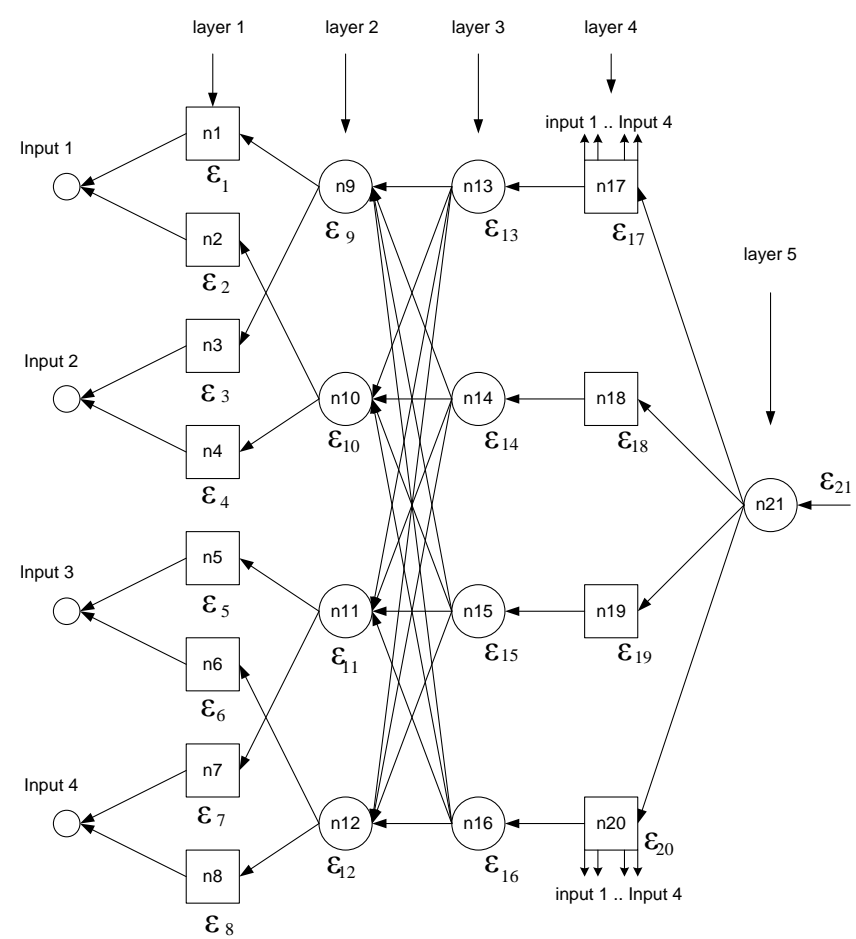

Fig. 6. The Backward Pass ANFIS structure

In learning using conventional gradient-based learning algorithms such as EBP and the Marquadt Lavenberg variant (LM) all parameters in the feedforward ANN must be determined manually. The parameters in question are input weight and hidden bias. These parameters are also interconnected between one layer to another, so that requires long learning speed and is often trapped on local minima [23].

Whereas in ELM parameters such as input weight and hidden can be chosen randomly, so ELM has a fast learning speed and is able to produce good generalization performance. In accordance with the training data format and validation data in Fig. 4, then the ELM structure is designed as shown in Fig.7.

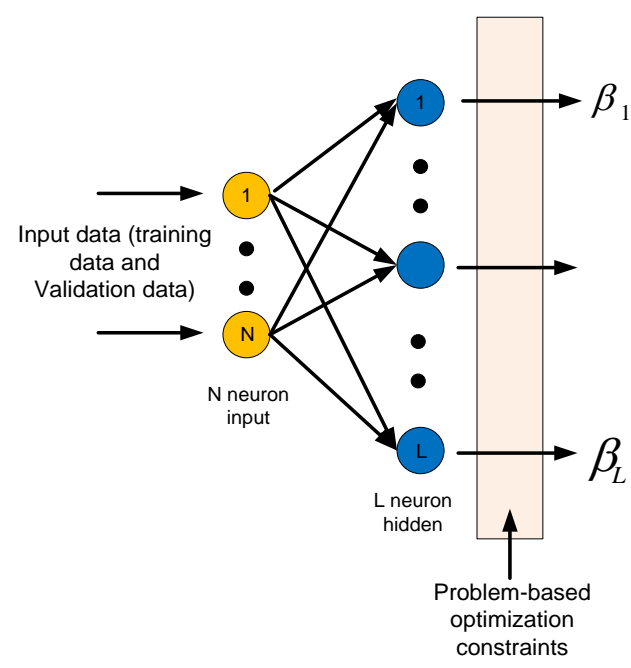

Fig. 7. The ELM structure 


\section{E. Flow diagram}

By the training data and validation data format in Fig. 4, as well as the ANFIS structure in Fig. 5 and Fig. 6, then the flowchart of the ANFIS training process and the ANFIS testing process for the $b$-value prediction that indicate earthquake potential, is designed as shown in Fig. 8 and Fig. 9.

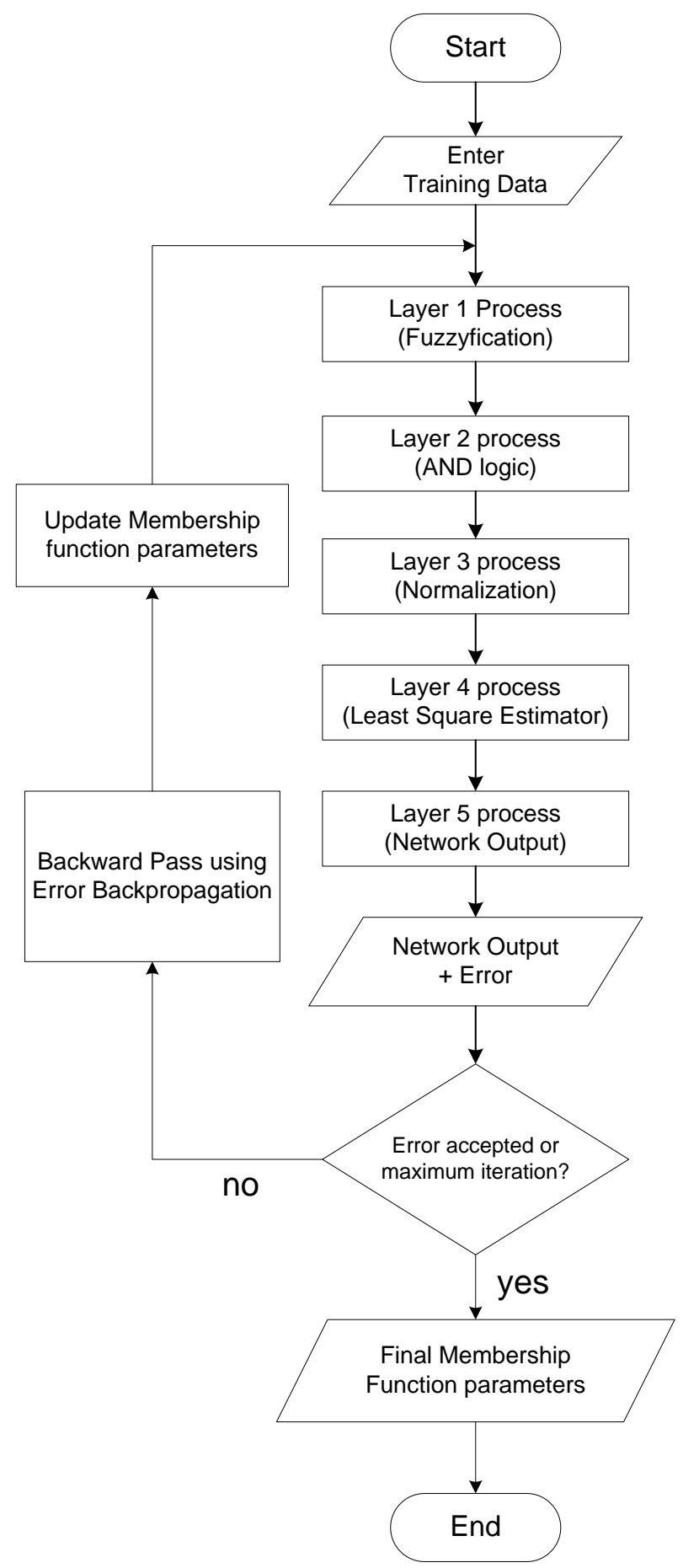

Fig. 8. The flowchart of the ANFIS training process

Whereas the flowchart of the ELM training process and testing process for $b$-value predictions that indicate earthquake potentialis designed as shown inFig. 10.

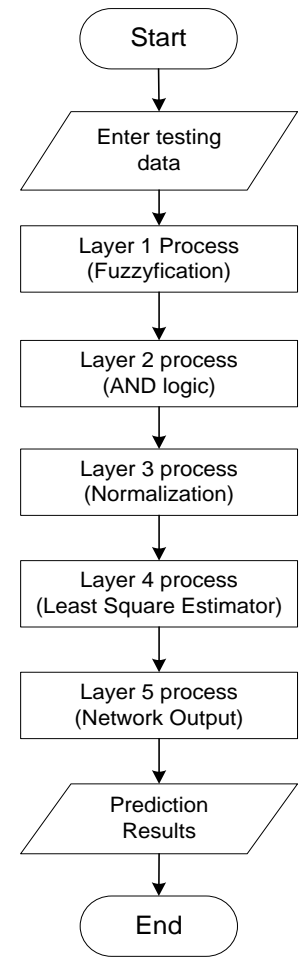

Fig. 9. The flowchart of the ANFIStesting process (prediction)

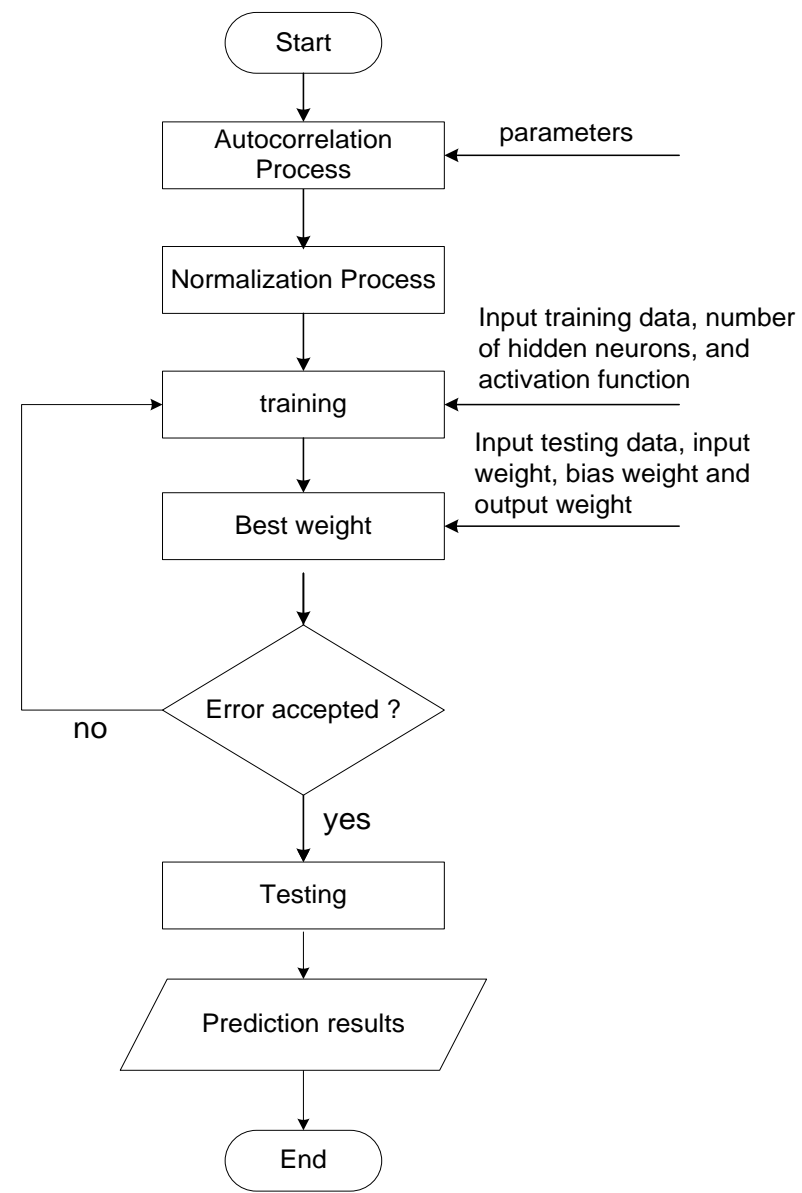

Fig. 10. The flowchart of ELM training process and testing process (prediction) 


\section{RESULTS AND DISCUSSION}

Furthermore, it will be tested the prediction of $b$-value that indicate the existence of earthquake potential, using the Neurofuzzy method with ANFIS structure and ELM method.

\section{A. ANFIS Training Results}

The results of the ANFIS training process are shown in Fig. 11 and Fig. 12
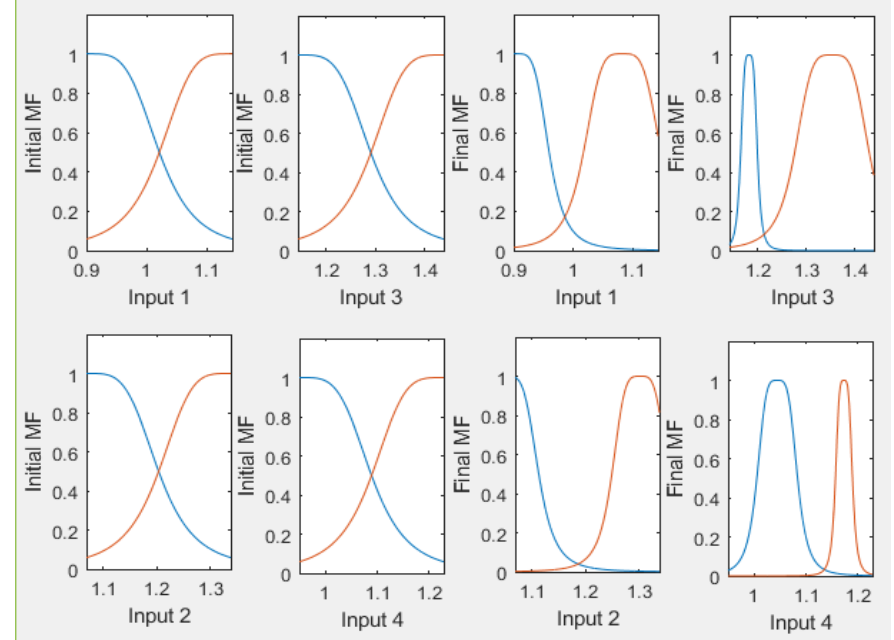

Fig. 11. The Membership function of ANFIS training results
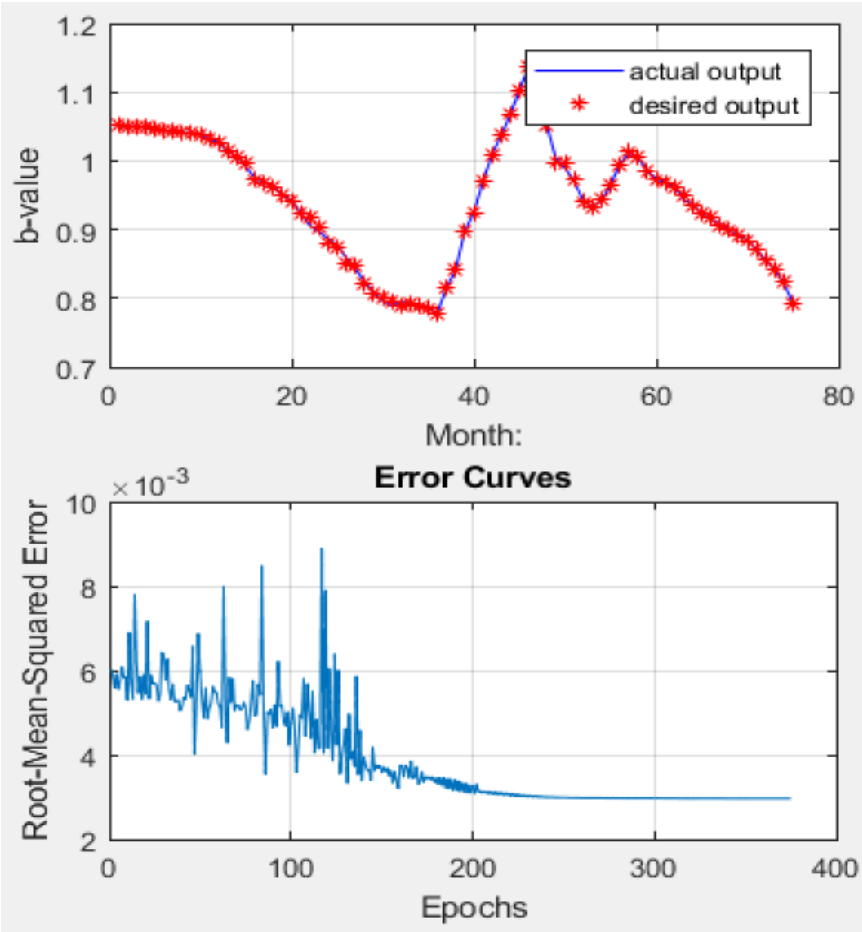

Fig. 12. The ANFIS training results

\section{B. ANFIS Testing Results}

The results of the ANFIS testing process for $b$-value predictions that indicate earthquake potential are shown in Fig.13.

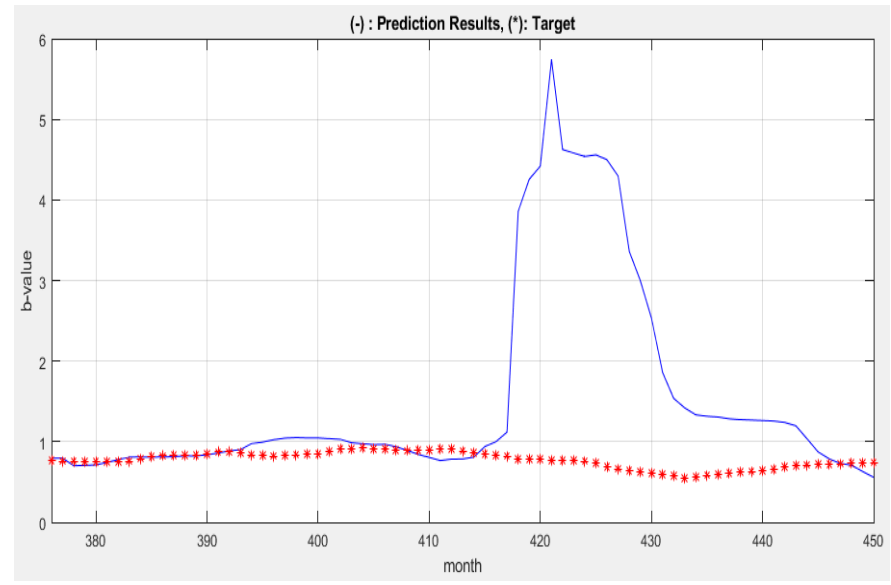

Fig. 13. The ANFIS testing results

\section{ELM Training Results}

The results of the ELM training process are shown in Fig.14.
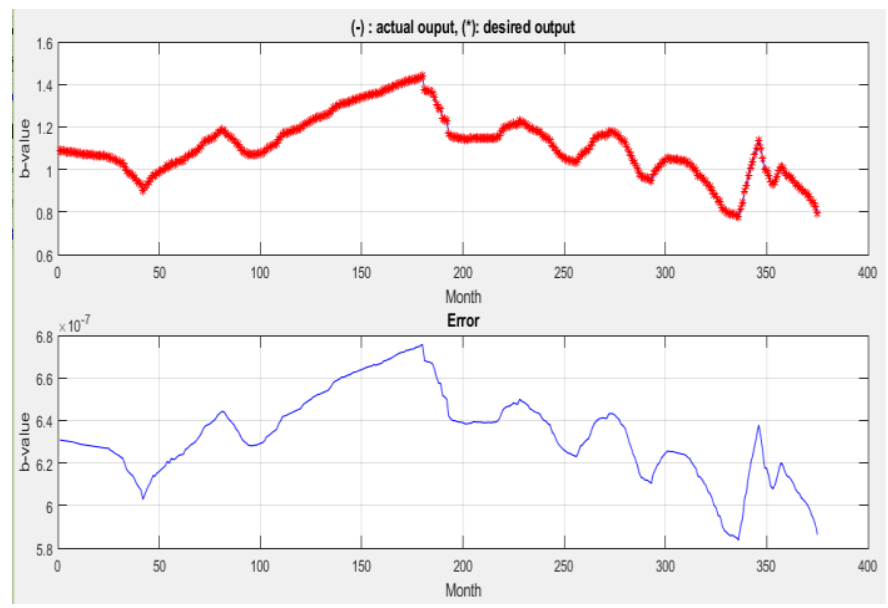

Fig. 14. The ELM training results

\section{ELM Testing Results}

The results of the ELM testing process for b-value predictions that indicate earthquake potential are shown in Fig.15.
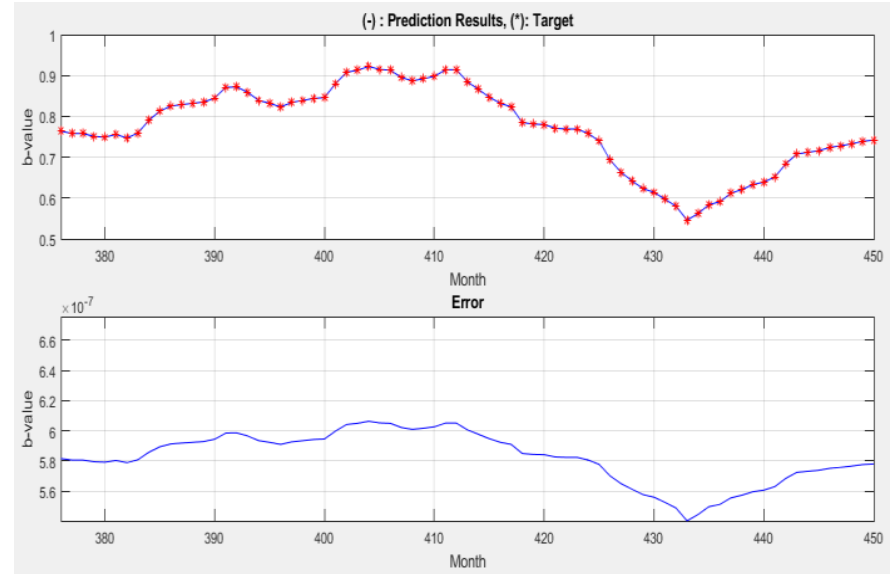

Fig. 15. The ELM testing results 


\section{E. Results Summary}

From the training and testing of experimental results for $b$ value predictions that indicate earthquake potential, using a neuro-fuzzy method with ANFIS structure and ELM method can be summarized in Table I and Table II.

TABLE I. TRAINING RESULTS

\begin{tabular}{|c|c|c|c|}
\hline Method & RMSE & MAPE & $\begin{array}{c}\text { Percentage of } \\
\text { success }\end{array}$ \\
\hline ANFIS & 0.00296375 & 0.223108 & 99.7769 \\
\hline ELM & $6.33494 \mathrm{e}-07$ & $5.77743 \mathrm{e}-05$ & 99.9999 \\
\hline
\end{tabular}

TABLE II. PREDICTION RESULTS

\begin{tabular}{|c|c|c|c|}
\hline Method & RMSE & MAPE & $\begin{array}{c}\text { Percentage of } \\
\text { success }\end{array}$ \\
\hline ANFIS & 1.50706 & 78.159 & 21.841 \\
\hline ELM & $6.25281 \mathrm{e}-07$ & $6.09082 \mathrm{e}-05$ & 99.9999 \\
\hline
\end{tabular}

\section{CONCLUSION}

From the experimental results in this earthquake prediction, it shows that the Extreme Learning Machine (ELM) method has better performance than Neuro-fuzzy with ANFIS structure. Superior performance, seen both during the training process and when used to predict b-value as a parameter that indicates the potential for an earthquake.

\section{ACKNOWLEDGMENT}

The first author is grateful to the Informatics Engineering Study Program and the Faculty of Computer Science of the Ministry of Research, Technology and High Education Universitas Pembangunan Nasional "Veteran" Jawa Timur for providing the opportunity to follow and fund the paper at the International Conference on Science and Technology (ICST) 2018.

\section{REFERENCES}

[1] W.B. Hamilton, "Tectonics of the Indonesian region," in US Geol. Surv. Prof. Pap., 1078, 345, 1979.

[2] B. dan G.V.K. Kundu, "Slab Detachment Of Subducted Indo-Australian Plate Beneath Sunda Arc, Indonesia," J. Earth Syst. Sci, vol.120, no. 193, pp. 193-204, 2011

[3] N. D. Sieh K., "Neotectonics of the Sumatran Fault Indonesia," J. Geophys. Res., vol. 105, pp. 28295-28326, 2000.

[4] M. Kaveh, V. R. Sharabiani, R. A. Chayjan, E. Taghinezhad, Y. Abbaspour-Gilandeh, and I. Golpour, "ANFIS and ANNs model for prediction of moisture diffusivity and specific energy consumption potato, garlic and cantaloupe drying under convective hot air dryer," Inf. Process. Agric., vol. 5, no. 3, pp. 372-387, 2018.

[5] M. Mostafaei, "ANFIS models for prediction of biodiesel fuels cetane number using desirability function," Fuel, vol. 216, pp. 665-672, 2018.

[6] B. Vakhshouri and S. Nejadi, "Prediction of compressive strength of self-compacting concrete by ANFIS models," Neurocomputing, vol. 280, pp. 13-22, 2018.

[7] E. Akkaya, "ANFIS based prediction model for biomass heating value using proximate analysis components," Fuel, vol. 180, pp. 687-693, 2016.

[8] J. Cheng and Y. Xiong, "Application of Extreme Learning Machine Combination Model for Dam Displacement Prediction," Procedia
Comput. Sci., vol. 107, pp. 373-378, 2017.

[9] Y. Ding, Y. Wang, and D. Zhou, "Mortality prediction for ICU patients combining just-in-time learning and extreme learning machine," Neurocomputing, vol. 281, pp. 12-19, 2018.

[10] Z. Liu, Y. Cheng, P. Wang, Y. Yu, and Y. Long, "A method for remaining useful life prediction of crystal oscillators using the Bayesian approach and extreme learning machine under uncertainty," Neurocomputing, vol. 305, pp. 27-38, 2018.

[11] B. Liu, S. Yan, H. You, Y. Dong, Y. Li, J. Lang, and R. Gu, "Road surface temperature prediction based on gradient extreme learning machine boosting," Comput. Ind., vol. 99, pp. 294-302, 2018.

[12] M. Atiquzzaman and J. Kandasamy, "Robustness of Extreme Learning Machine in the prediction of hydrological flow series," Comput. Geosci., 2018.

[13] C. F. Gutenberg B. dan Richter, "Frequency of earthquakes in California, Bull.," Seism. Soc. Am., vol. 34, 1944.

[14] Wiemer S. and M. Wyss, "Mapping spatial variability of the frequencymagnitude distribution of earthquakes," Adv. Geophys, vol. 45, pp. 259 302, 2002.

[15] S. W. Schorlemmer D. and M. Wyss, "Earthquake statistics at Parkfield, Stationarity of b-values," J. Geophys. Res., vol. 109, no. B12307, 2004.

[16] T. Ustu, "A method in determining the value of $b$ in a formula $\log n=a$ - bM showing the magnitude frequency for earthquakes," Geophys. Bull. Hokkaido Univ., vol. 13, pp. 99-103, 1965.

[17] Shi Y. and B. A. Bolt, "The standard error of the magnitude-frequency b value,” Bull. Seism. Soc. Am., vol. 72, pp. 1677-1687, 1982.

[18] S. Kumar, "Seismicity In The Nw Himalaya, India: Fractal Dimension, B-Value Mapping And Temporal Variations For Hazard Evaluation," Geosci. Res., vol. 3, pp. 83-87, 2012.

[19] S. N. A. N. Pratiwi Rohadi, "Analisis korelasi variasi spasial dan temporal b-value terhadap stress, seismisitas, dan tektonik di pulau bali, lombok, dan Sumbawa," Jurnal. Geofis., vol. 13, no. 2/2012, 2012.

[20] B. Sunardi, "Analisa Fraktal Dan Rasio Slip Daerah Bali-Ntb Berdasarkan Pemetaan Variasi Parameter Tektonik," J. Meteorol. dan Geofis., vol. 10, pp. 58-65, 2009.

[21] S. Rohadi, "Studi Seismotektonik Sebagai Indikator Potensi Gempa bumi Di Wilayah Indonesia," J. Meteorol. Dan Geofis., vol. 10, pp. 111120, 2009.

[22] G.-B. Huang, Q.-Y. Zhu, and C.-K. Siew, "Extreme learning machine: theory and applications," Neurocomputing, vol. 70, no. 1, pp. 489-501, 2006.

[23] G.-B. Huang, M.-B. Li, L. Chen, and C.-K. Siew, "Incremental extreme learning machine with fully complex hidden nodes," Neurocomputing, vol. 71, no. 4, pp. 576-583, 2008. 